\title{
Antonio Candido de Mello e Souza e Florestan Fernandes: BREVES PERFIS
}

\section{Claudinei Carlos Spirandelli ${ }^{1}$}

\begin{abstract}
RESUMO
Este artigo enfoca, de maneira didática, perfis e trajetórias de importantes sociólogos paulistas: Antonio Candido de Mello e Souza e Florestan Fernandes. Nosso texto pretende mostrar suas origens, características de obras, os grupos sob suas lideranças e heranças legadas. Neste artigo, pretendemos uma melhor divulgação desses grandes nomes da sociologia brasileira.
\end{abstract}

Palavras-chave: Sociologia da cultura. História intelectual. Pensamento brasileiro. Sociologia uspiana.

\section{Antonio Candido de Mello e Souza and Florestan FERNANDES: BRIEF PROFILES}

\begin{abstract}
This article focuses, in a didactic way, profiles and trajectories of major sociologists from the state of São Paulo: Antonio Candido de Mello e Souza and Florestan

\footnotetext{
1 Possui bacharelado e licenciatura plena em Ciências Sociais (1994), mestrado em Sociologia (2001) e doutorado em Sociologia (2008), todos pela FFLCH-USP. Tem experiência na área de Sociologia, com ênfase em sociologia da cultura e em pensamento sociológico brasileiro, atuando, principalmente, nos seguintes temas: sociologia brasileira, sociologia da vida intelectual e teoria sociológica. Professor-colaborador adjunto no Departamento de Ciências Sociais da Universidade Estadual de Londrina-UEL/PR. End. eletrônico: cspirandelli@hotmail.com
} 
Fernandes. Our text intends to show our origins, characteristics of works, the groups under their leaders and heritage bequeathed. In this article, we want a better dissemination of the great names of Brazilian sociology.

Keywords: Sociology of culture. Intellectual history. Brazilian thought. Uspian sociology.

\section{INTRODUÇÃO: A CRIAÇÃO DA FFCL-USP}

história e a importância dos cientistas sociais paulistas Antonio Candido de
Mello e Souza e Florestan Fernandes estão ligadas à fundação da Faculdade
de Filosofia, Ciências e Letras (FFCL) e da Universidade de São Paulo (USP), que a abrangia² ${ }^{2}$ Esta, surgida em 1934, encamparia as já existentes Faculdade de Medicina, Escola Politécnica, Faculdade de Direito do Largo de São Francisco, Faculdade de Farmácia e Odontologia, bem como outros institutos educacionais, museus e entidades de pesquisa isoladas. Após 1969, a FFCL passaria ser a atual Faculdade de Filosofia, Letras e Ciência Humanas (FFLCH).

AcriaçãodaUniversidade, pordecretodo governopaulista, eraumainiciativa de setores "esclarecidos" da elite do estado e pretendia a "modernização" (nos moldes dos países liberal-democrático-capitalistas), a formação e a diversificação dos quadros desse setor (CARDOSO, 1982). Além dela, surgia na capital paulista, em 1933, a Escola Livre de Sociologia e Política de São Paulo, norte-americana e privada, trazendo Donald Pierson, Horace Davis e Samuel Löwrie, entre outros.

\footnotetext{
${ }^{2}$ Nosso trabalho se inspira, modesta e parcialmente, nas ideias de disputas simbólicas dentro de campos que, segundo Pierre Bourdieu, relacionam-se ao espaço das dimensões de lutas por poder e influência. Também é essencial a menção a Norbert Elias, tendo em vista o fato de ser possível atentar às relações que constrangimentos, exigências, necessidades e demandas de grupos sociais teriam para com a produção individual de um intelectual, balizando, de certa forma, sua autonomia e obras. Isso poderia circunscrever até que ponto as realizações humanas seriam produtos negociados entre determinações sociais e escolhas individuais. Ressaltamos também o pertencimento de nossas análises a tradições ligadas à história social das classes ou, no caso, dos grupos produtores de cultura, sobretudo no universo dos intelectuais e da dinâmica de suas relações. Nesse caso, intentamos diálogos com Max Weber (1991) no que concerne a seus estudos sobre os letrados chineses (os integrantes de camadas instruídas e de setores econômicos e políticos dominantes, intelectualmente treinados, formados nos quadros da religião confuciana, capacitados para atividades burocráticas e estatais e justificativas teológicas para as estratificações sociais). Este artigo deve ser tomado didaticamente, servindo mais como divulgação da importância dos autores enfocados para a sociologia brasileira.
} 
Em seu início, a Universidade paulista importou modelos universitários europeus e norte-americanos, as missões européias, com professores e cientistas, no intuito de formar docentes e pesquisadores de alto nível e quadros profissionais para a burocracia de estado. Esses modelos estrangeiros, as missões, geraram os primeiros programas, projetos, currículos e forneceram as diretrizes do futuro mercado de trabalho das novas profissões (MICELI, 2001a). Assim, vieram Roger Bastide, Paul Arbousse-Bastide, Claude Lévi-Strauss, Fernand Braudel, Georges Gurvitch, Jean Mauguié, Pierre Monbeig, Gilles Ganton Granger, Charles Morazé, Paul Hugon, Émile G. Leonard, entre outros, que ajudaram a desenvolver as primeiras gerações de cientistas sociais acadêmicos do Brasil, imbuídas de maior precisão e rigor científicos, típicos da ciência realizada nos países desenvolvidos. A nova instituição universitária empreendia, dessa forma, um novo modelo de produção intelectual, diferente do estilo ensaístico, diletante e generalizante, típico dos autores anteriores à década de 1940, em sua maioria, jornalistas, bacharéis e escritores (MICELI, 2001b), estranho ao método cientificista europeu e norteamericano - apesar desse "diferente" não significar simplesmente, melhor ou pior.

Dessa forma, São Paulo transformava-se num importante centro das Ciências Sociais no país, implantando padrões de excelência em ensino e pesquisa (MICELI, 2001). Além disso, nessa nascente Faculdade de Filosofia da USP eram criados outros cursos, como Filosofia, Pedagogia, Biologia, História, Química, dentro outros.

A primeira geração da instituição se caracterizaria por alunos como Antonio Candido de Mello e Souza, Gilda de Mello e Souza, Lourival Gomes Machado, Paulo Emilio Salles Gomes, Decio de Almeida Prado etc. Eles traziam para a Universidade as características de seu segmento social, os setores eruditos da elite, ligados à fruição de obras de arte (literatura, cinema, teatro, etc.) e à fluência em línguas européias. De outro lado, também adentravam a Universidade, mas em minoria, alunos oriundos de segmentos proletários e humildes.

\section{1 - Antonio Candido de Mello e Souza}

0 crítico literário Antonio Candido de Mello e Souza nasceu na cidade do Rio de Janeiro (RJ) em 1918. Logo se mudou para Santa Rita de Cássia e Poços de Caldas, ambas no Sudoeste de Minas Gerais. Era membro de uma oligárquica e tradicional família mineiro-fluminense, que proporcionou grande formação humanística ao menino. Ela era composta por amantes da leitura; o pai era um culto médico, entusiasta dos estudos sobre o Brasil. Aos dez anos, o menino e 
a família passam um grande período na Europa, sediados em Paris. No Velho Mundo, ele se apegaria ao gosto refinado dos livros, iniciado por professoras particulares. Isso continuaria após o retorno ao Brasil, com outras preceptoras e 0 incentivo do pai (JACKSON, 2002).

Mudou-se para São Paulo em 1936 com o objetivo de aprofundar os estudos; tal se deu em meio à fermentação cultural da cidade grande, com seus concertos, livrarias, exposições e Mário de Andrade dirigindo o Departamento de Cultura do município. Ingressou, em 1939, na então subseção de Ciências Sociais e Políticas, da FFCL-USP (e no Curso de Direito da USP, no Largo de São Francisco, que abandonaria no último ano). Licenciou-se em 1941. Após a formatura, começou, em 1942, a trabalhar como professor de sociologia na FFCL-USP, no cargo de primeiro assistente da Cadeira de Sociologia II, regida por Fernando de Azevedo.

Iniciaria, ainda em 1939, a chamada "geração de Clima", ao lado dos amigos Décio de Almeida Prado, Lourival Gomes Machado, Ruy Galvão de Andrada Coelho, Paulo Emilio Salles Gomes e Gilda de Moraes Rocha (com quem se casaria em 1943). Com esses amigos criaria, em 1941, a revista Clima. Juntos, esses autores se lançavam na cena cultural paulistana através de um tipo de trabalho intelectual, o da crítica às artes - 0 teatro, o cinema, a literatura e as artes plásticas. Durante a década de 1940, Antonio Candido de Mello e Souza escreveria sobre literatura para a Folha da Manhã e o Diário de São Paulo, e textos de militância política para a Folha Socialista. Sob seu comando e o de Décio de Almeida Prado, surgia o Suplemento Literário, editado entre 1956 e 1967.

Em 1945, publicou Introdução ao método crítico de Silvio Romero. Nesse ano, a obra foi apresentada como tese ao concurso para a Cadeira de Literatura Brasileira. Apesar de ter obtido o segundo lugar e o título de livre-docente em Literatura, Antonio Candido de Mello e Souza teve de permanecer como professor assistente de Sociologia na Cadeira de Sociologia II até 1958, pois não havia "espaço institucional" para abrigá-lo no Curso de Letras da FFCL-USP.

Em 1954, defendeu a tese de doutoramento em sociologia Os parceiros do Rio Bonito: estudo sobre a crise nos meios de subsistência do caipira paulista, publicada dez anos depois. Baseando-se em Marx (a influência dos meios de vida como fator de sociabilidade no trabalho e a definição de identidade do homem face à natureza) e em conceitos antropológicos de Redfield, Malinowski, Richards, Evans-Pritchard e Lévi-Strauss, o sociólogo Antonio Candido de Mello e Souza estudou a obtenção dos meios de vida como fator central da sociabilidade entre os caipiras. Ele analisa a cultura e a sociedade rústicas como modalidades que 
correspondem a etapas diferentes no processo de urbanização e secularização, como se os momentos sucessivos de tempo se revelassem por meio de variação no espaço. Nesse trabalho, Antonio Candido de Mello e Souza problematiza a transição de "parceiro" a empregado assalariado, no mundo rural.

Descrevendo uma realidade e um processo específicos (o fenômeno da urbanização no estado de São Paulo), ele analisa a decomposição da vida caipira, a sociabilidade do homem do campo e localiza num aspecto da vida social, $a$ obtenção dos meios de vida, o fator dinâmico dessa sociabilidade e solidariedade. 0 livro é uma ampla interpretação da formação social brasileira, conforme Luiz C. Jakcson (2002). Ainda, segundo o autor, a cultura caipira seria produto híbrido do catolicismo missionário e jesuítico do período colonial, porque incorporaria formas indígenas nos ritos católicos, que ganhariam vitalidade com a libertação dos índios administrados por essa ordem, em meados do século XVIII. Ou seja, aquilo que era híbrido e residual se tornaria substantivo e próprio. Nesse século, com férteis mixagens raciais e culturais, difundiam-se a mentalidade e a vida social com estilo "barrocos", mesmo entre os pobres e as comunidades caipiras. Os sinais disso sobreviveriam na delicada fidalguia do homem comum dos antigos redutos caipiras, conforme José de Souza Martins, em entrevista (JACKSON, 2002). As características do caipira seriam próprias de um sistema de economia fechado ou semi-fechado, ligada ao povoamento disperso. A isso se relacionam suas formas de sociabilidade.

Em 1957, o sociólogo publica sua principal obra, Formação da literatura brasileira: momentos decisivos (MELLO E SOUZA, 2000), iniciada em 1946. Nesse livro ele trabalha, de modo original, a noção de sistema (para a literatura brasileira) como algo a ser percebido nas relações constantes, repetitivas e observadas "empiricamente" - na produção literária - na sociedade. É dado que um sistema, para existir, fundamentar-se ou funcionar, precisa de uma estrutura que lhe dê suporte. No sistema literário proposto, o que o tornaria "perfeito" seria o fato de possuir o esquema de interação autor-obra-público, o qual teria se constituído entre o arcadismo e o romantismo no País (grosso modo, entre 1750 e 1850). Assim, o autor defende a idéia da constituição de uma razoável tradição literária nacional relativamente estável, desde meados do século XVIII; e ele privilegia o meio no qual uma obra está inscrita, em lugar da mensagem por ela definida (esse aparato conceitual mostra a sustentação e a força da obra).

Nesse livro, ele indica também que a relação entre a formação social e a literária revelaria descompassos entre ambas, pois elas seriam independentes e 
autônomas. A razão disso é o fato de o Brasil ter, desde fins do século XVIII, um sistema literário definido e completo, mas sem ter formação social similar. Além disso, no sistema literário nacional que desenvolveu, o autor tratou de assunto que dizia respeito, no limite, a escritores cujo desejo era fazer uma literatura brasileira ou nacional diferente da literatura de outros países. Naturalmente, tais emaranhados e amplos leques de questões não foram aceitos tranquilamente. Houve divergências e polêmicas, que, de resto, são mesmo esperadas quando se abordam temas dessa forma - com essas explanações, esperamos apenas ter esboçado essencialidades das discussões.

Outra questão também tratada pelo sociólogo é a da adaptação de ideias estrangeiras no Brasil na época. Por esse prisma, apenas a literatura, no país, teria obtido relativa autonomia, diferentemente das esferas nacionais da política, da economia e da ciência, as quais talvez ainda não passassem de "manifestações". Dizemos isso a partir da afirmação do autor, que se referia a toda literatura pré-árcade aqui produzida como manifestações literárias, não literatura propriamente dita, consolidada, com um sistema completo, eficiente e configurando uma tradição. Eis, da mesma forma, a política nacional, a economia e as ciências. Isso reforçaria e mostraria um fosso ou descompasso entre a formação social e a formação literária.

Segundo o ensaísta Paulo Arantes (ARANTES, 1997), Antonio Candido de Mello e Souza daria forma metódica ao conteúdo básico da experiência intelectual brasileira e equacionaria a problemática da formação do Brasil como um todo. Já para Abdalla Junior (1999), o livro Formação da literatura brasileira vem a público num período otimista, o do pós-guerra, de afirmação da autonomia de diversas nações subjugadas até então e de descolonização. Inseria-se num momento de compreensão de um novo Brasil, posterior às grandes interpretações dos anos 1930. os "letrados" ou "intelectuais" de agora, avessos a certos ufanismos, demandam a tomada de consciência do "subdesenvolvimento".

Após a defesa de sua tese de doutoramento, em 1954, ele começaria a construir sua transição da carreira de cientista social para a de crítico literário. Transfere-se para o então Instituto Isolado de Ensino Superior do Estado, em AssisSP (atual UNESP dessa cidade) em 1958, na função de professor de literatura brasileira. Ficaria até 1961, quando, enfim, retorna à USP, como professor colaborador, para assumir a recém-criada Cadeira de Teoria Literária e Literatura Comparada. Nessa década, foi também professor de literatura brasileira no exterior, na Universidade de Paris (1964-1966) e na Universidade de Yale (1968). 
Em 1974, tornou-se, por concurso, professor titular da Cadeira de Teoria Literária e Literatura Comparada. Em 1977, transferiu-se para o Departamento de Letras da UNICAMP-SP, pelo qual se aposentaria em 1978. Outras de suas importantes obras são Tese e antítese (1964), Literatura e sociedade (1965), A educação pela noite e outros ensaios (1987), Recortes (1993) e O discurso e a cidade (1993).

\section{Florestan Fernandes}

Florestan Fernandes nasceu em São Paulo (SP) em julho de 1920, filho da lavadeira Maria Fernandes, imigrante portuguesa humilde e analfabeta, e de pai desconhecido. Pobre, trabalhou como engraxate, garçom e cozinheiro, entre outros empregos. Conseguiu, com interrupções e atrasos, terminar a madureza (equivalente ao atual supletivo para o ensino médio).

Ingressou, em 1941, na então subsecção de Ciências Sociais e Políticas da FFCL-USP, formando-se em 1944. Em 1945, começou a lecionar sociologia na referida instituição. Foi professor assistente na Cadeira de Sociologia II de 1945 a 1954; regente da Cadeira de Sociologia I de 1954 a 1964; professor catedrático de Sociologia I de 1964 a 1969, quando foi aposentado compulsoriamente pelo governo militar. Finalmente, obteve o título honorífico de professor emérito, no ano de 1985 (a partir de 1969, com a extinção do regime de cátedras, o cargo/ título mais alto da instituição universitária seria o de professor titular).

Ele criou importante linhagem de pesquisa para a compreensão da sociedade brasileira. Estudou as relações entre grupos humanos tradicionais e a sociedade brasileira moderna, o preconceito racial e as mudanças culturais e sociais em nossa sociedade, retomando, assim, o "marco zero" dos duros processos de transição da anterior sociedade estamental para a atual sociedade de classes. Afirmava que a sociedade brasileira moderna repousava numa dualidade, apresentando aspectos arcaizantes, rústicos ou tradicionais e, ao mesmo tempo, modernos (D’INCA0, 1987). Os fundamentos teórico-metodológicos básicos do sociólogo paulista encontravam-se, em seu início, na escola funcionalista, sobretudo. Com esse instrumental, realizou as primeiras pesquisas que deram início à carreira acadêmica.

Lançou seus primeiros artigos sociológicos (JACKSON, 2004) ainda em 1943, centrados na análise da dimensão da cultura de qual viera, o folclore da capital paulista. Os trabalhos sobre o tema originariam Folclore e mudança social na cidade de São Paulo, em 1961. Ele realizou estudos sobre o negro e o 
preconceito racial, com Relações raciais entre negros e brancos em São Paulo, de 1955 e A integração do negro na sociedade de classes, de 1964.

Também possui importância pelas obras referentes à teoria e metodologia sociológicas e o sistema de economia de mercado (ou capitalismo) no Brasil, respectivamente em Organização social dos Tupinambás, de 1947, A função social da guerra na sociedade Tupinambá, de 1951, Ensaio sobre o método de interpretação funcionalista na sociologia, de 1953, Mudanças sociais no Brasil, de 1960, A sociologia numa era de revolução social, de 1962, Sociedade de classes e subdesenvolvimento, de 1968, e A revolução burguesa no Brasil: ensaio de interpretação sociológica, de 1975. Na maioria desses escritos estão suas análises críticas, as quais se debruçam sobre os fundamentos e contradições da organização social brasileira, o capitalismo (dependente) nacional e a "luta de classes" no país.

A obra desse sociólogo é, em certa medida, também fruto de interlocuções e incorporações com as tradições ou correntes crítico-dialética e weberiana; além dessas, ele dialogou com diversos outros autores. Por isso, ao abordamos a construção de seu pensamento, devemos evitar o clichê segundo a qual o mesmo teria realizado uma síntese das três importantes escolas clássicas da sociologia. Ele não apenas realizou tal síntese, mas encampou criativa e criticamente diversas correntes e autores, como Bastide, Gurvitch, Mannheim, Freyer, Tönnies, Von Wiese, Park, Merton, Wright Mills (ARRUDA, 1995). A sua história se confunde com a da institucionalização dos cursos de Ciências Sociais no país, a partir do já relatado surgimento da antiga FFCL-USP (ARRUDA, 1995).

A produtividade de Florestan Fernandes era também irmanada ao seu engajamento político. A sua história esteve sempre ligada a uma luta peculiar, lecionando, pesquisando e discursando contra as mazelas nacionais. Ele participara, nas décadas de 1950 e 1960, das campanhas pela educação laica e pública, por exemplo. Opondo-se aos governos militares pós-1964, foi aposentado em 1969.

Sem possuir a formação educacional/erudita dos colegas abastados, acabaria por institucionalizar nova linguagem, dentro de rigoroso formato acadêmico, de cientificidade, ensinado pelos mestres europeus. 0 desfecho de sua história seria desenvolver a chamada "escola sociológica paulista" (ARRUDA, 1995). A sua projeção, contudo, iria se delinear ainda nos anos 1950, quando se esboçava o Projeto UNESCO (órgão da ONU sediado em Paris), em conjunto com a Universidade de Columbia, nos EUA, e que realizaria estudos raciais nos estados de Pernambuco, Bahia, Rio de Janeiro e São Paulo. Por seu lado, A USP e a Revista 
Anhembi, do intelectual Paulo Duarte, iniciaram pesquisas na região sul do Brasil, com Roger Bastide e Florestan Fernandes, chefiando os então jovens sociólogos Fernando Henrique Cardoso, Octavio Ianni e Renato Jardim Moreira, entre outros. Os dois projetos se somaram visando um estudo completo da população negra e das relações raciais no País. A UNESCO pretendia estudar a relativa situação de harmonia social que existiria no Brasil.

0 resultado foi o estudo Relações raciais entre negros e brancos em São Paulo, com Roger Bastide. Seus autores concluíram que a miscigenação não seria a tradução de uma sociedade democrática ou igualitária. Para o sociólogo paulista, o escravismo gerara uma sociedade estratificada que, convertendo-se de agrícola em industrial, deixa a melhor parte de suas oportunidades aos brancos; assim, ele começa a ver, no conflito de raças, uma "luta de classes".

Logrando êxito com empreendimentos intelectuais dessa envergadura, começa a esboçar-se a "escola sociológica paulista". Com o passar do tempo, tal "escola" ou padrão de trabalho dos cientistas sociais da FFCL-USP se consolida, tendo Florestan Fernandes e sua Cadeira de Sociologia I à frente, também com destaque de Fernando Henrique Cardoso ${ }^{3}$, Octavio Ianni, José de Souza Martins, Francisco Corrêa Weffort, Maria Sylvia de Carvalho Franco e Leôncio Martins Rodrigues Netto (ARRUDA, 1995). Tais pessoas herdariam idéias e o modus operandi de fazer ciência do mestre. Entre os desdobramentos da "escola" ou do pensamento florestaniano, está o projeto, dirigido pelo próprio, chamado Economia e sociedade no Brasil: análise sociológica do subdesenvolvimento e o Centro de Sociologia Industrial e do Trabalho, o CESIT, criado em 1962 por Florestan Fernandes e por seu então assistente Fernando Henrique Cardoso, e extinto em 1969.

Apesar de tudo, é importante mencionar o fato de que Florestan Fernandes nunca concordara com a idéia de ter liderado uma escola sociológica, como

\footnotetext{
${ }^{3}$ Integrante da chamada "escola sociológica paulista", a ela deve parte de sua importância, posto que fora um dos principais colaboradores de Florestan Fernandes. Junto deste e de Octavio Ianni, participou das campanhas pela escola pública, pela laicidade do ensino, numa época de grandes debates sobre a modernização da sociedade brasileira como um todo, momento em que os cientistas se sentiam compelidos por esses compromissos sociais. A Cadeira de Sociologia I tinha um projeto "social", preocupada que estava com a escola pública, laica e gratuita, além da modernização das relações sociais no Brasil, do empresariado, do Estado e da classe operária. Fernando Henrique Cardoso foi também um dos líderes do grupo dos Seminários de Marx (SCHWARZ, 1999), que renovaria, criticamente, o pensamento acadêmico e o pensamento político das chamadas "esquerdas" no Brasil, à época.
} 
propõe José de Souza Martins (MARTINS, 1998). Para Florestan Fernandes, isso seria "falta de imaginação", e ele a recusaria por não querer confundir as análises do grupo como "doutrina" (FERNANDES, 1977). 0 sociólogo paulista, no entanto, reconhecia que esse grupo, se não chegou a consumar uma "escola" nos moldes de uma Escola de Chicago, desdobrou indagações, problemáticas e interpretações sobre a sociedade brasileira (FERNANDES, 1977). Nada mais justo, pois, desde os anos 1950, o sociólogo em foco já dava forma à "escola paulista", sobrepondo a monografia, a pesquisa e o estudo ao ensaio (o "aristocrático" e, como ele prefere, "estamental" modo de fazer ciência de então). Nisso, concordamos com Martins, pois a temática e a metodologia de pesquisa e de análise desenvolvidas por Florestan Fernandes e seus assistentes pautariam uma tradição no pensamento sociológico que se irradiaria numa pluralidade de estudos a respeito das questões sociais (BASTOS, 2002).

A despeito da respeitabilidade da sociologia de Florestan Fernandes e seu grupo, ele não conquistou unanimidade no restante do país à época. A análise crítica utilizada por ele e seu grupo diferenciavam-se do estilo do pernambucano Gilberto Freyre, por exemplo. A forma, o estilo "ensaístico", as ideias e conclusões da sociologia deste eram vistas com descrédito e como inferiores às do modelo de análise "acadêmica" e "crítica" iniciada na USP pelo sociólogo paulista.

Também o baiano Guerreiro Ramos era outro que discordava das visões desenvolvidas pela "escola paulista". Dizia que tal modo de fazer ciência era por demais "importado", "colonizado" pelos povos "dominadores" (europeus e americanos). Defendia uma sociologia "autêntica", "brasileira" (RAMOS, 1957; OLIVEIRA, 1995), enquanto que para Florestan Fernandes, a ciência adquiriria respeitabilidade e respaldo se fosse trabalhada em termos universais. As polêmicas duraram anos e Guerreiro Ramos acabou ficando em posição subalterna na sociologia brasileira por muito tempo. De qualquer forma, críticas à parte, a "escola sociológica paulista" se impôs nos debates acadêmicos.

Na trajetória de Florestan Fernandes, um elemento a ser recuperado é o fato de seu estrato social de origem, a camada proletária pobre, ser caracterizado por regras de etiqueta diferentes das existentes na camada social de seus colegas de segmentos abastados. As misérias econômica e educacional e a luta pela sobrevivência teriam nele desenvolvido padrões e regras outros que não os da troca de gentilezas, típicas do estrato elitista, e educação formal. Talvez por isso ele tenha sido detentor de comportamento e personalidade bastante autocráticos. 
Os relatos sobre suas atitudes profissionais para com colegas, interlocutores ou críticos denotam grosserias e desqualificações do oponente (GARCIA, 2002). É comum encontrarmos, em escritos do sociólogo, a respeito da infância, uma espécie de heroicização e autocondescendência com ela, beirando a pieguice. Essa infância é utilizada como atributo positivo por elogiosos discípulos e estudiosos (MARTINEZ, 1998; IMAMURA, 1995; D'INCA0, 1987; GARCIA, 2002; MARTINS, 1998; SOARES, 1997). Octavio Ianni, por exemplo, destaca frases de seu mestre, como "eu nunca teria sido o sociólogo em que me converti sem o meu passado"; ou "iniciei a minha aprendizagem 'sociológica' aos seis anos, quando precisei ganhar a vida como se fosse um adulto" (FERNANDES apud IANNI, 1983).

Com tal histórico, não seria à toa que conseguiria passar célere por cima das dificuldades a ponto de quase suplantar os outros colegas cientistas na USP, enquanto ativo nela. A ambição e a certeza da capacidade, desenvolvidas na dureza de seus primeiros anos de vida, podem ser percebidas nesta sua frase “(...) alcancei a estatura de um artesão que domina e ama o seu mister, porque sabe como deve praticá-lo e para o que ele serve" (FERNANDES, 1977, p. 175).

Nesse sentido, a respeito de aspectos da vida de Florestan Fernandes, Fernanda Peixoto (2000) comenta os vínculos do sociólogo paulistano com Roger Bastide quando aluno deste, ao ingressar na USP, o que teria permitido-lhe ampliar os horizontes, auxiliando na minimização de seus velhos laços de pertencimento social, por se integrar a um grupo profissional e intelectual universitário. De modo persistente, ele teria "travado uma luta simbólica" (aspas nossas), no plano da linguagem, conforme Sylvia G. Garcia (GARCIA, 2002), para legitimar e consolidar a sua sociologia. Teria conseguido, assim, tornar sua cadeira um importante centro de pesquisa sociológica no Brasil.

Não seria exagero afirmar que Florestan Fernandes, destituído dos trunfos sociais e culturais de seus colegas, converteu a carreira no único espaço possível para angariar prestígio intelectual e se firmar socialmente, diz a estudiosa de sua obra, Maria Arminda do Nascimento Arruda (1995). Assim, aproveitando-se de um ambiente aberto, porque dominado pelo "meritocratismo cientificista" europeu, Florestan Fernandes teria sabido tirar proveito das situações, mesmo as mais adversas, tanto na vida pré-universitária quanto na universitária (GARCIA, 2002).

\section{CONSIDERAÇõeS FINAIS}

Procuramos nos concentrar na vida e obra dos dois cientistas sociais dentro do período que termina, grosso modo, em fins da década de 1960. No caso de 
Antonio Candido de Mello e Souza, pelo fato de, nessa época, ele ter acabado de reprocessar-se em outra área, qual seja, a de crítica e estudos literários. Enquanto isso, Florestan Fernandes, exilado, daria início à militância política efetiva, tendo ido lecionar em universidades pela América do Norte (Columbia, Toronto e Stanford). Retornou ao Brasil em meados da década seguinte para, a partir daí, dar maior relevo à sua situação de militante político, já esboçada em anos anteriores, além de lecionar na PUC paulistana. Nos últimos decênios de vida, depois da redemocratização de 1985, produziria artigos para a imprensa, relativos à política; como militante político-partidário, elegeu-se deputado federal constituinte pelo PT paulista em 1986, reelegendo-se quatro anos depois, somente deixando a atividade parlamentar em fins de 1994, um ano antes de seu falecimento, ocorrido em 1995.

Mas, para o crítico literário, os encaminhamentos na referida década de 1960 se deram pelo fato de 0 ambiente em que os dois cientistas frequentavam ter se tornado impossível de se habitar, qual seja, o espaço das Ciências Sociais da FFCLUSP. Com Florestan Fernandes e seu grupo na Cadeira de Sociologia I operando análises voltadas à estrutura da sociedade brasileira e ao "desenvolvimento" no Brasil, o lado ligado à organicidade cultural das diversas formações sociais dessa mesma sociedade era subalternizado.

Assim como a grande contribuição de Florestan Fernandes foi a criação do conceito de capitalismo dependente (que se definiria por um modo específico de desenvolvimento capitalista dentro do capitalismo monopolista, sendo tal constructo buscado no conceito de dependência, de Lênin, e criticamente trabalhado), Fernando Henrique Cardoso, seu discípulo e assistente, ficou mais tarde conhecido por ter criado, juntamente com o chileno Enzo Faletto, a chamada teoria da dependência. Grosso modo, segundo essa teoria, o Brasil (ou os países "subdesenvolvidos") seria um "sócio-menor" no desenvolvimento capitalista global. Ou seja, uma parceria subalterna, que o "imperialismo" acabara por desenvolver. Assim, os estudos da Cadeira de Sociologia I atuavam nesse sentido, o da caminhada do país, no início dos governos militares, para a situação de capitalismo dependente.

De outro lado, Antonio Candido de Mello e Souza, com sua análise dos "parceiros", no estudo do caipira, recupera a formação histórica dessa especificidade cultural paulista e, com ela, uma dimensão fundamental do passado brasileiro. A análise da mudança social sugere uma desintegração da cultura caipira diante do processo de modernização do país e admite a existência 
relativamente autônoma, embora precária e ameaçada, da civilização rústica constituída durante a colonização, nos interstícios da sociedade centralizada no latifúndio agro-exportador. Assim, contribui para a compreensão do modo como as contradições sociais se colocavam na sociedade brasileira de então, em termos de pluralidades de tempos históricos, além de expor a problemática da transição cultural (estudo típico da década de 1950), de inspiração antropológica, sobre os bloqueios às mudanças e sobre as lentidões no processo social que se chocavam com o desenvolvimentismo.

Nesse sentido, é um contraste com Florestan Fernandes que pensava as grandes formas culturais como provenientes das macro-formações sociais. Além disso, Antonio Candido de Mello e Souza, na Cadeira de Sociologia II, atuava ao lado de Maria Isaura Pereira de Queiroz, que pensava de modo semelhante a este, com seus estudos sobre religiosidade rústica, campesinato, formações culturais rurais e coronelato. Até mesmo na forma do texto, ambos, filhos de famílias ligadas à aristocracia e à fruição em línguas, literatura e cultura erudita, identificavam-se. Florestan Fernandes, tendo outra origem, "reinventou-se": seus parágrafos eram herméticos, frios e pesados, contrastando com a leveza vocabular. Nesse sentido, há similitudes entre a situação de Durkheim e seus "oponentes" na vida intelectual francesas, os poderosos literatos Balzac, Flaubert e Victor Hugo, entre outros.

Mas, enquanto poderia haver nos escritos de Antonio Candido de Mello e Souza, especificamente no estudo dos caipiras, um sutil tom de lamento e nostalgia por um mundo que se desmoronava, o da secular construção patriarcal das famílias e de formação culturais pré-capitalistas; Florestan Fernandes e seu grupo pensavam no futuro, na superação do "atraso". Este sociólogo obriga ao contraste, quer se aceite ou não. Daí, os reprocessamentos feitos pelo primeiro.

Outro elemento que moldava as disputas e as obras dos cientistas era o fato de que parte do contingente de estudantes e futuros cientistas sociais, oriundos da pequena classe média emergente e do proletariado descendente de primeira geração de imigrantes na capital paulista, era capturada pelo canto de sereia florestaniano.

Aliás, devemos ressaltar que Florestan Fernandes, estudando as relações sociais e a estrutura de classes da sociedade brasileira, toma por conclusão o fato de que a burguesia brasileira teria construído seu poder a partir de uma espécie de mandonismo oligárquico, de controle autocrático e paternalista. Ou seja, os revolucionários burgueses teriam construído uma pseudo-democracia. Nesse 
sentido, seu trabalho continua, em grande parte, útil para a compreensão de questões relativas à atual configuração de nossa sociedade, posto que ela possui uma democracia frágil, sem fundamentos plenamente consolidados, frutos de uma burguesia anódina e autocrática e de "esquerdas" monolíticas e autoritárias. E nenhum desses lados possui compromissos com a democracia efetiva. Por seu lado, os estudos sociológicos de Antonio Candido de Mello e Souza, com as retomadas das diversidades de estudos da antropologia na contemporaneidade, estão fortemente na ordem do dia. Eis os legados dos dois cientistas sociais, que devem ser sempre reforçados.

Finalizando, podemos dizer que as compreensões sobre intelectuais/artistas e suas inserções sociais podem carrear novas interpretações às obras deles, posto que não apenas estas, mas as histórias de vida, classes social, atitudes, grupos socioculturais de origem, bem como as regras dos pequenos mundos acadêmicos, podem determinar boa parte das transformações científicas e intelectuais de um país. É o caso das vidas, origens, histórias e obras de Antonio Candido de Mello e Souza e de Florestan Fernandes. Ao iniciarem seus trabalhos com a sociologia, encontraram-na de um jeito; meio século depois, se ela desenvolveu outros contornos, foi, em boa parte, devido a tais cientistas.

\section{REFERÊNCIAS}

ABDALLA JUNIOR, Benjamin. Antonio Candido: Formação da literatura brasileira. In: MOTA, Lourenço Dantas (org.). Introdução ao Brasil: um banquete no trópico. São Paulo: SENAC, 1999.

ARANTES, Paulo Eduardo; ARANTES, Otília Beatriz Fiori. Sentido da formação: três estudos sobre Antônio Candido, Gilda de Mello \& Souza e Lúcio Costa. Rio de Janeiro: Paz e Terra, 1997.

ARRUDA, Maria Arminda do Nascimento. A sociologia no Brasil: Florestan Fernandes e a "escola paulista". In: MICELI, Sérgio (org.). História das ciências sociais no Brasil. São Paulo: Sumaré, 1995. Vol. 2.

BASTOS, Élide Rugai. Pensamento social da escola sociológica paulista. In: MICELI, Sergio (org.). O que ler na ciência social brasileira 4 (1970-2002). São Paulo: ANPOCS, Sumaré; Brasília (DF): CAPES, 2002.

BOURDIEU, Pierre. As regras da arte: gênese e estrutura do campo literário. São Paulo: Companhia das Letras, 1996. 
. A economia das trocas simbólicas. São Paulo: Perspectiva, 1974.

CARDOSO, Irene de A. R. A universidade da comunhão paulista: o projeto de criação da Universidade de São Paulo. São Paulo: Cortez, 1982.

COHN, Gabriel. Padrões e dilemas: o pensamento de Florestan Fernandes. In: MORAES, Reginaldo et allii (orgs.). Inteligência brasileira. São Paulo: Brasiliense, 1986.

D'INCA0, Maria Ângela. (org.). O saber militante: ensaios sobre Florestan Fernandes. Rio de Janeiro: Paz e Terra; São Paulo: UNESP, 1987.

ELIAS, Norbert. Mozart: sociologia de um gênio. Rio de Janeiro: Jorge Zahar, 1995. FERNANDES, Florestan. A condição de sociólogo. São Paulo: Editora Hucitec, 1978. . A sociologia no Brasil: contribuição para o estudo de sua formação e desenvolvimento. Petrópolis: Vozes, 1977.

. Florestan Fernandes por ele mesmo. Estudos Avançados, São Paulo, v. 10, n. 26, jan./abr. 1995a, pp. 129-172. (Organização de Bárbara Freytag)

FORACCHI, Marialice Menccarini (org.). Mannheim: sociologia. São Paulo: Ática, 1982.

GARCIA, Sylvia Gemignani. Destino impar: sobre a formação de Florestan Fernandes. São Paulo: 34, 2002.

IANNI, Octavio. Florestan Fernandes: sociologia. São Paulo: Ática, 1983.

IMAMURA, Avelar Cezar. Florestan Fernandes: a sociologia como paixão. São Paulo: FFLCH/USP, 1995. Dissertação (Mestrado em História).

JACKSON, Luiz Carlos. A sociologia paulista nas revistas especializadas (19401965). Tempo Social, São Paulo, v.16, n.1, pp. 263-283, junho de 2004.

. A tradição esquecida: os parceiros do Rio Bonito e a sociologia de Antonio Candido. Belo Horizonte: UFMG; São Paulo: FAPESP, 2002.

. Gerações pioneiras na Sociologia paulista (1934-1969). Tempo social, São Paulo, v. 19, n. 1, 2007. Disponível em: bttp://www.scielo.br/pdf/ts/v19n1/ a07v19n1.pdf Acesso em: 10 jan. 2008.

LEPENIES, Wolf. As três culturas. São Paulo: Edusp, 1996.

LIMONGI, Fernando. Mentores e clientelas na Universidade de São Paulo. In: MICELI, Sergio (org.). História das ciências sociais no Brasil. São Paulo: Sumaré, 2001. Vol. 1. 
MARTINEZ, Paulo (org.).Florestan ou o sentido das coisas. São Paulo: Boitempo, 1998.

MARTINS, José de Souza. Florestan: sociologia e consciência social no Brasil. São Paulo: Edusp, 1998.

MELLO E SOUZA, Antonio Candido de. Florestan Fernandes. São Paulo: Fundação Perseu Abramo, 2001.

Os parceiros do Rio Bonito: estudo sobre o caipira paulista e a transformação dos seus meios de vida. São Paulo: Duas Cidades; Ed. 34, 2001b. Formação da literatura brasileira: momentos decisivos. Belo Horizonte: Itatiaia, 2000.

MICELI, Sérgio (org.). História das ciências sociais no Brasil. São Paulo: Sumaré, 2001a. Vol. 1. . Intelectuais à brasileira. São Paulo: Companhia das Letras, 2001b. (org.). História das ciências sociais no Brasil. São Paulo: Sumaré; FAPESP, 1995. Vol. 2.

OLIVEIRA, Lúcia Lippi. A sociologia do Guerreiro. Rio de Janeiro: UFRJ, 1995.

PEIXOTO, Fernanda Arêas. Diálogos brasileiros: uma análise da obra de Roger Bastide. São Paulo: EDUSP, 2000.

PONTES, Heloisa. Destinos mistos: os críticos do Grupo Clima em São Paulo (1940-1968). São Paulo: Companhia das Letras, 1998.

RAMOS, Guerreiro Antonio. Introdução crítica à sociologia brasileira. Rio de Janeiro: Andes Ltda., 1957 (3a. parte).

ROMÃO, Wagner de Melo. A experiência do Cesit: sociologia e política acadêmica nos anos 1960. Dissertação de Mestrado, Sociologia, FFLCH/USP, São Paulo: 2003. SCHWARZ, Roberto. Um seminário de Marx. In: Seqüências brasileiras: ensaios. São Paulo, Companhia das Letras, 1999. pp. 86-105.

SOARES, Eliane Veras. Florestan Fernandes: o militante solitário. São Paulo: MEC/Funarte, 1996.

WEBER, Max. Sociologia da religião (tipos de relações comunitárias religiosas). In: Economia e sociedade: fundamentos da Sociologia compreensiva. Brasília (DF): Editora UnB; São Paulo: Imprensa Oficial do Estado de São Paulo, 1999. Vol. I. . Ensayos sobre sociología de la religión. Madrid: Taurus, 1991 (3 volumes). 